\title{
Effect of deferiprone or deferoxamine on right ventricular function in thalassemia major patients with myocardial iron overload
}

\author{
Gillian C Smith ${ }^{1,2 \dagger}{ }^{+}$Francisco Alpendurada $^{1 \dagger}$, John Paul Carpenter ${ }^{1,2}$, Mohammed H Alam, ${ }^{1,2}$, Vasili Berdoukas ${ }^{3}$, \\ Markissia Karagiorga ${ }^{4}$, Vasili Ladis ${ }^{4}$, Antonio Piga ${ }^{5}$, Athanassios Aessopos ${ }^{6}$, Efstathios D Gotsis ${ }^{7}$, Mark A Tanner ${ }^{8}$, \\ Mark A Westwood ${ }^{9}$, Renzo Galanello ${ }^{10}$, Michael Roughton ${ }^{11}$ and Dudley J Pennell ${ }^{1,2^{*}}$
}

\begin{abstract}
Background: Thalassaemia major (TM) patients need regular blood transfusions that lead to accumulation of iron and death from heart failure. Deferiprone has been reported to be superior to deferoxamine for the removal of cardiac iron and improvement in left ventricular (LV) function but little is known of their relative effects on the right ventricle (RV), which is being increasingly recognised as an important prognostic factor in cardiomyopathy. Therefore data from a prospective randomised controlled trial $(R C T)$ comparing these chelators was retrospectively analysed to assess the RV responses to these drugs.
\end{abstract}

Methods: In the RCT, 61 TM patients were randomised to receive either deferiprone or deferoxamine monotherapy, and CMR scans for T2* and cardiac function were obtained. Data were re-analysed for RV volumes and function at baseline, and after 6 and 12 months of treatment.

Results: From baseline to 12 months, deferiprone reduced RV end systolic volume (ESV) from 37.7 to $34.2 \mathrm{~mL}$ ( $p=$ 0.014), whilst RV ejection fraction (EF) increased from 69.6 to $72.2 \%(p=0.001)$. This was associated with a 27\% increase in $T 2^{*}(p<0.001)$ and $3.1 \%$ increase in LVEF $(p<0.001)$. By contrast, deferoxamine showed no change in RVESV (38.1 to $39.1 \mathrm{~mL}, \mathrm{p}=0.38)$, or RVEF (70.0 to $69.9 \%, p=0.93$ ) whereas the T2* increased by $13 \%(p<0.001)$, but with no change in LVEF $(0.32 \% ; p=0.66)$. Analysis of between drugs treatment effects, showed significant improvements favouring deferiprone with a mean effect on RVESV of $-1.82 \mathrm{~mL}(p=0.013)$ and $1.16 \%$ for RVEF $(p=0.008)$. Using regression analysis the improvement in RVEF at 12 months was shown to be greater in patients with lower baseline EF values $(p<$ $0.001)$, with a significant difference in RVEF of 3.5\% favouring deferiprone over deferoxamine $(p=0.012)$.

Conclusion: In this retrospective analysis of a prospective RCT, deferiprone monotherapy was superior to deferoxamine for improvement in RVEF and end-systolic volume. This improvement in the RV volumes and function may contribute to the improved cardiac outcomes seen with deferiprone.

\section{Introduction}

Blood transfusions are standard therapy for patients with $\beta$-thalassaemia major (TM) and prevent death in childhood, but although clinical status and short term survival improve, each unit of blood contains about 200-250 mg of iron which the body cannot eliminate, which leads to long term iron accumulation. Patients treated only with

\footnotetext{
* Correspondence: d.pennell@imperial.ac.uk

+ Contributed equally

'CMR Unit, Royal Brompton \& Harefield NHS Foundation Trust, Sydney

Street, London SW3 6NP, UK

Full list of author information is available at the end of the article
}

blood transfusions may die in the second and third decades of life from the complications of iron overload, in particular heart failure [1,2]. Myocyte damage is related to the production of reactive oxygen species (ROS) formed as levels of labile iron rise, which cause oxidative damage to membranes and mitochondrial respiratory chain enzyme dysfunction $[3,4]$. Chelation therapy can reduce tissue iron levels and the incidence of cardiac complications, but patients at risk need to be accurately profiled for appropriate treatment. The cardiovascular magnetic resonance (CMR) relaxation parameter $\mathrm{T} 2 \%$ is

\section{Biomed Central}


sensitive to storage tissue iron in haemosiderin because of the creation of field inhomogeneities by iron particles, and the clinical adoption of this technique is now widespread as a mainstay of cardiac iron overload assessment and treatment,[5-7] with important capability to predict future cardiac events, [8] and evidence of significant beneficial effects on cardiac mortality [9].

Deferoxamine was the first iron chelating agent for clinical use and became standard therapy in the 1970s. It is a large positively charged lipophobic molecule, is poorly absorbed by the digestive system and has a short plasma half life $[10,11]$. It is therefore administered subcutaneously using a portable syringe system usually overnight typically 5 times per week. This therapy can be very problematic with poor compliance, and a number of factors result in long-term cardiac iron accumulation with its use [12]. The second clinical iron chelator was deferiprone, which is a much smaller neutrally charged lipophilic molecule which allows good gastrointestinal absorption and cellular access $[10,11]$. The plasma half life is longer allowing oral administration with three doses per day. Direct comparison trials show that deferiprone has greater efficacy than deferoxamine for reducing myocardial iron loading and improving left ventricular (LV) systolic function $[13,14]$. However, there is a paucity of data related to the effects of these chelators on the right ventricle (RV), which is known to be an important independent predictor of outcome in dilated cardiomyopathy,[15] and ischaemic heart disease [16-18]. Recent papers have established the normal ranges for RV volumetric parameters for non-iron loaded TM patients and shown a significant relation between $\mathrm{T} 2$ * and RV ejection fraction (RVEF), including a small percentage of patients with impaired RVEF but normal LVEF $[19,20]$. In order to identify and compare the effects of deferiprone and deferoxamine, we reanalyzed the CMR images for the LA16 trial, which was a randomized controlled trial (RCT) comparing the 2 drugs [14]. Our hypothesis was that deferiprone would improve RV function more than deferoxamine.

\section{Methods}

The LA16 RCT consisted of 61 regularly transfused patients with TM from 4 centres in Greece and Italy [14]. All patients were previously treated with subcutaneous deferoxamine monotherapy. Inclusion criteria included a T2* between 8 and $20 \mathrm{~ms}$ and LVEF greater than 56\% based on the lower normal limit for non-anaemic subjects from previously published data [21]. No patient had heart failure symptoms. Deferiprone was allocated to 29 patients (actual dose $92 \mathrm{mg} / \mathrm{kg}$ daily) whilst 32 patients were allocated to continue with deferoxamine therapy (dose of $43 \mathrm{mg} / \mathrm{kg} /$ day overnight for an average of 5.7 days per week). Written informed consent was obtained according to local ethics committee approval.
Iron loading and cardiac function was assessed using CMR. The T2* sequences were installed at the local CMR facilities, Athens (GE CVi) and Cagliari (GE Signa). The technique was validated by scanning phantoms of known $\mathrm{T}^{*}$ and testing intra-site reproducibility by scanning 5 patients twice at the local centre. The same patients were scanned at the reference site in London (Siemens Sonata) for inter-site reproducibility. A coefficient of variation $(\mathrm{CV}) \leq 15 \%$ was defined as acceptable. Site inter-study variability was $2.4 \%$ for Cagliari and 3.5\% for Athens. Comparison with the reference site yielded CVs of $1.6 \%$ and $9.7 \%$ respectively. Volumetric data were acquired using a steady state free precession sequence (FIESTA). A set of contiguous short axis cines were acquired to give complete coverage of both ventricles. Care was taken to place the basal slice parallel to the atrioventricular groove. Slice thickness was $8 \mathrm{~mm}$ with a spacing of $10 \mathrm{~mm}$. No patient had a history of, and no CMR scan showed any features of pulmonary hypertension (normal pulmonary artery size, no right ventricular hypertrophy, no systolic septal flattening). Patients were scanned between 3 and 10 days post transfusion at baseline, 6 months and 12 months after entering the trial. T2* values and LV volumetric data were assessed previously using a CMR viewing and analysis software package CMRtools (Cardiovascular imaging solutions, London, UK) [14]. LV function was assessed in the RCT using an early version of the analysis package in which LV volumes are quantified manually using direct surface planimetry, and therefore for consistency we elected to use the same version of the software to analyze the RV thus eliminating the need for right sided valve tracking. Care was taken to include blood volume below the pulmonary valve. Basal regions with thin, non trabeculated muscle were considered atrial and were excluded. Papillary muscles were also excluded from the blood pool [22]. Although local blinding to the treatment arm was not possible due to the nature of drug administration (oral for deferiprone and subcutaneous for deferoxamine), all remote scan analysis performed at the core-lab in London was fully blinded to treatment. Study treatment was unblinded on completion of LV and $\mathrm{T}^{*}$ analysis. For the analysis of the RV volumetric data, all data sets were anonymized and analyzed in random order using the same analysis package by experienced operators blinded to treatment arm and LV response. To assess reproducibility, data-sets with an improvement in RVEF $\geq 5 \%$ at 12 months were reprocessed blindly.

\section{Statistical analysis}

Continuous variables were compared using a paired t-test. $\mathrm{T} 2$ * values were log transformed and changes expressed as geometric mean with coefficient of variation. Between groups comparison of drug effects were assessed using a 
repeated measurement ANOVA. Statistical significance was set at $\mathrm{p}<0.05$. To quantify reproducibility the coefficient of variance $(\mathrm{CV})$ was calculated.

\section{Results}

Full data on the LA16 study have been published including the patient demographics,[14] but the important trial summary findings are repeated here. In the deferiprone group 27 patients completed the study; 2 patients withdrew due to adverse events (elevated hepatic enzymes, in one case probably due to cytomegalovirus). In the deferoxamine group, 29 patients completed; 1 patient withdrew secondary to a reduction in LV function and 2 for personal reasons. The patient groups were well matched at baseline for cardiac T2*, LV volumes and function and RV volumes and function (table 1). Baseline RVEF was within the normal reference range for thalassaemia patients,[19] except for one patient in the deferoxamine group (RVEF 1\% below the normal range). Patient compliance was similar for both groups. Myocardial T2* improved by $18 \%$ at 6 months $(\mathrm{p}<0.001)$ and $27 \%$ at 12 months $(\mathrm{p}<0.001)$ in the deferiprone arm. The LVEF rose by $2.0 \%$ from $69.7 \%$ at baseline to $71.7 \%$ at 6 months ( $<<0.001)$ and by $3.1 \%$ to 72.7 at 12 months $(\mathrm{p}<0.001)$. With deferoxamine therapy, T2* improved by $9 \%$ at 6 months $(\mathrm{p}=0.003)$ and by $13 \%$ at 12 months ( $<<0.001$ ) but LVEF was unchanged being $68.4 \%$ at baseline and 68.7 at 6 months $(+0.52 \%, \mathrm{p}=0.42)$ and 68.5 at 12 months $(+0.32 \%, \mathrm{p}=$ $0.66)$.

Table 1 Baseline values for cardiac volume and function parameters

\begin{tabular}{|c|c|c|c|}
\hline & Deferiprone & Deferoxamine & $p$ \\
\hline No. Patients randomized & 28 & 32 & \\
\hline Age & $25.1 \pm 3.8$ & $26.6 \pm 4.7$ & 0.33 \\
\hline Male sex (\%) & $15(52)$ & $16(50)$ & 0.99 \\
\hline Weight (kg) & $57.7 \pm 7.9$ & $60.6 \pm 13.2$ & 0.30 \\
\hline \multicolumn{4}{|l|}{ Cardiac parameters } \\
\hline Myocardial T2* (ms) & $13.0(32 \%)$ & $13.3(30 \%)$ & 0.77 \\
\hline LVEDV (mL) & $134 \pm 32$ & $132 \pm 23$ & 0.81 \\
\hline LVESV (mL) & $43 \pm 14$ & $41 \pm 13$ & 0.51 \\
\hline LVEF (\%) & $69.7 \pm 5.4$ & $68.4 \pm 4.9$ & 0.34 \\
\hline RVEDV (mL) & $122.5 \pm 24.9$ & $124.7 \pm 27.7$ & 0.75 \\
\hline RVESV (mL) & $37.7 \pm 11.7$ & $38.1 \pm 12.6$ & 0.90 \\
\hline RVEF (\%) & $69.6 \pm 5.2$ & $70.0 \pm 5.8$ & 0.79 \\
\hline \multicolumn{4}{|l|}{ Biochemical markers } \\
\hline Liver iron concentration $(\mu \mathrm{g} / \mathrm{L})$ & $6.16 \pm 6.0$ & $6.32 \pm 5.8$ & 0.92 \\
\hline Serum ferritin $(\mu \mathrm{g} / \mathrm{L})$ & $1791 \pm 1029$ & $2795 \pm 2441$ & 0.039 \\
\hline \multicolumn{4}{|c|}{ Haematology } \\
\hline Transfusional iron (mL/kg/year) & $152 \pm 43.4$ & $144 \pm 44.4$ & 0.53 \\
\hline Haemoglobin level (g/L) & $105 \pm 12.0$ & $113 \pm 11.9$ & 0.023 \\
\hline
\end{tabular}

Values are mean \pm SD except for $\mathrm{T}^{*}$ where values are geometric mean with CV.
In the current analysis, the RV mean volumetric and T2* values are detailed in table 2 . To summarise, in the deferiprone arm RV end-diastolic volume (EDV) was stable, RV end-systolic volume (ESV) decreased significantly from 37.7 to $34.2 \mathrm{~mL}$ at 12 months ( $\mathrm{p}=0.014)$; and RVEF increased from $69.6 \%$ to $72.2 \%$ ( $\mathrm{p}=0.001$ ). For the patients on deferoxamine therapy, the changes in RV parameters from baseline to 12 months showed no significant difference. Analysis of between drugs treatment effects using a repeated measurement ANOVA (table 3) showed significant differences favouring deferiprone for the reduction of RV ESV ( $p=0.014$ at 12 months, Figure 1) and improvement in RVEF ( $\mathrm{p}=$ 0.008 at 12 months, Figure 2). Non significant differences between drugs were found for RV EDV. With regression analysis, the change in RVEF was found to be inversely related to the baseline EF $(p<0.001)$ with a significant difference between drugs favouring deferiprone by a mean of $3.5 \%$ (95\% CI 0.8 to $6.3 \%$; p = 0.012). The reduction in RVESV over 12 months was also related to the baseline ESV value with borderline significance $(p=0.051)$, and there was a significant difference between drugs favouring deferiprone by a mean of $4.5 \mathrm{~mL}$ more than patients on deferoxamine $(95 \% \mathrm{CI}$ 1.2 to $7.8 \mathrm{~mL} ; \mathrm{p}=0.009$ ). Therefore the patients benefitting most from deferiprone treatment are those with the lower baseline values of RVEF. The CV for intra-observer study RVEF measurement was $2.4 \%$ at baseline and $2.0 \%$ at 12 months. There was no relation between change in RVEF and change in LVEF $(r=0.3, p=0.9)$.

\section{Discussion}

RV volumetric and functional parameters have been difficult to measure using conventional imaging techniques due to the irregular geometry of the RV chamber, the size and quantity of the RV trabeculae, and the proximity of the RV to the chest wall which impairs echocardiographic assessment. CMR suffers less from these drawbacks because of its inherent 3D nature and high blood to myocardium contrast and is therefore considered to be the most accurate and reproducible technique for assessing RV volumes and EF [23,24]. Attention to correct definition of the basal slice during acquisition and subsequent analysis is however pivotal. The improved confidence of measuring RV volumes and function from CMR and other techniques has assisted the understanding the importance of the RV in cardiac disease. RVEF is an important predictor of outcome in dilated cardiomyopathy, which is both independent of and incremental to LV EF [15]. The predictive value of RV function has also been shown in congenital heart disease,[25-27] chronic systolic dysfunction, [28] and ischemic heart failure, $[16,17,29,30]$ with RVEF being shown to be an independent predictor of outcome 
Table 2 RV volumetric parameters at baseline, 6 and 12 months (mean \pm SD) in the 2 treatment arms

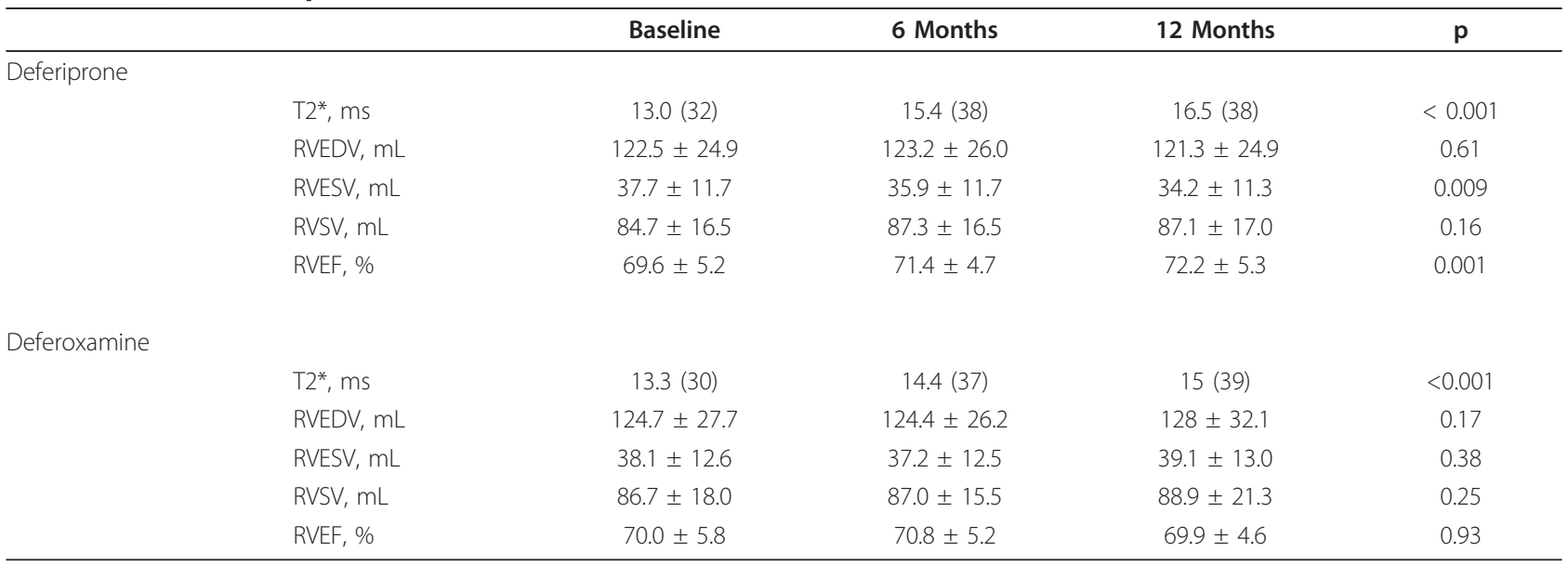

The $\mathrm{T}^{*}$ values show the geometric mean and CV. The $\mathrm{p}$ value reflects the change from baseline to 12 months.

$[16,17]$. Accordingly, the effects of myocardial iron loading on RV function may be important in thalassaemia patients.

In the current study, we found a significant improvement in RVEF (increase) and RVESV (reduction) with deferiprone therapy. These improvements parallel the previously reported LV response [14]. There was no significant increase in RVEDV suggesting loading conditions did not play an important role. A flat RV response was seen in the deferoxamine group, which again mirrors LV behaviour. The between groups analysis showed superiority for deferiprone over deferoxamine for both the reduction in RVESV and the increase in RVEF. The magnitude of improvement in RVEF and reduction in RVESV were greater for patients with a higher ESV and lower EF at baseline. Interestingly neither LVEF nor RVEF improved significantly in the deferoxamine group despite the improvement in $\mathrm{T}_{2} *$. The cause for this difference in functional response is not fully understood, but the explanation may lie in the additional effects of deferiprone on restoring normal cardiac mitochondrial function,[31] possibly through effects on reducing reactive oxygen species [32].

There is little other data relating RV function changes with the iron chelators, but a recently published abstract

Table 3 Between drug effect on RV volumetric parameters showing a significant difference in RV ESV and RVEF favouring deferiprone.

\begin{tabular}{lcccc}
\hline \multicolumn{5}{c}{ Treatment effect } \\
Deferiprone-Deferoxamine \\
Mean & \multicolumn{2}{c}{$\mathbf{9 5 \%} \mathbf{~ C l}$} & $\mathbf{p}$ \\
\hline EDV & -1.21 & -4.44 & 2.03 & 0.47 \\
ESV & -1.82 & -3.27 & -0.37 & 0.014 \\
SV & 0.64 & -2.02 & 3.31 & 0.64 \\
EF & 1.16 & 0.30 & 2.01 & 0.008 \\
\hline
\end{tabular}

relating to a longitudinal trial of the efficacy of deferasirox in myocardial siderosis, [33] showed a significant improvement in myocardial iron levels with an improvement in RVEF at 1 year, but no change in LV function at 1,[34] 2,[35] and 3 [36] years of follow up. The significance of this discrepancy between RV and LV response to deferasirox is not currently clear, though it is possible that the RV response is an early signal of myocardial iron clearance as LV compliance and filling pressure improves.

\section{Limitations}

Data acquisition for this study was originally designed to assess the change in $\mathrm{T} 2 \%$ and LV functional parameters in response to therapy. Therefore no RV long axis images were obtained to construct 3-dimentional models for volumetric analysis, but the requirement for this was removed by using direct manual planimetry for quantitative analysis of RV volumes. Pulmonary arterial pressure was not systematically measured using echocardiography of the tricuspid regurgitant jet, but here was no CMR evidence of raised pulmonary artery pressure in our patients, and pulmonary hypertension is rare in well treated thalassaemia major [37]. Direct RV measurement of $\mathrm{T} 2 *$ would have been interesting in this population to compare with changes in RV volumes and function, however, it is challenging to measure $\mathrm{T} 2 \%$ in the thin wall of the RV and this was not attempted in the randomized controlled trial.

\section{Conclusions}

This study has shown that RVESV decreased and RVEF improved with deferiprone monotherapy and this beneficial response was superior to deferoxamine. RV volumetric and function parameters have in the past been neglected when reporting the efficacy of iron chelators 


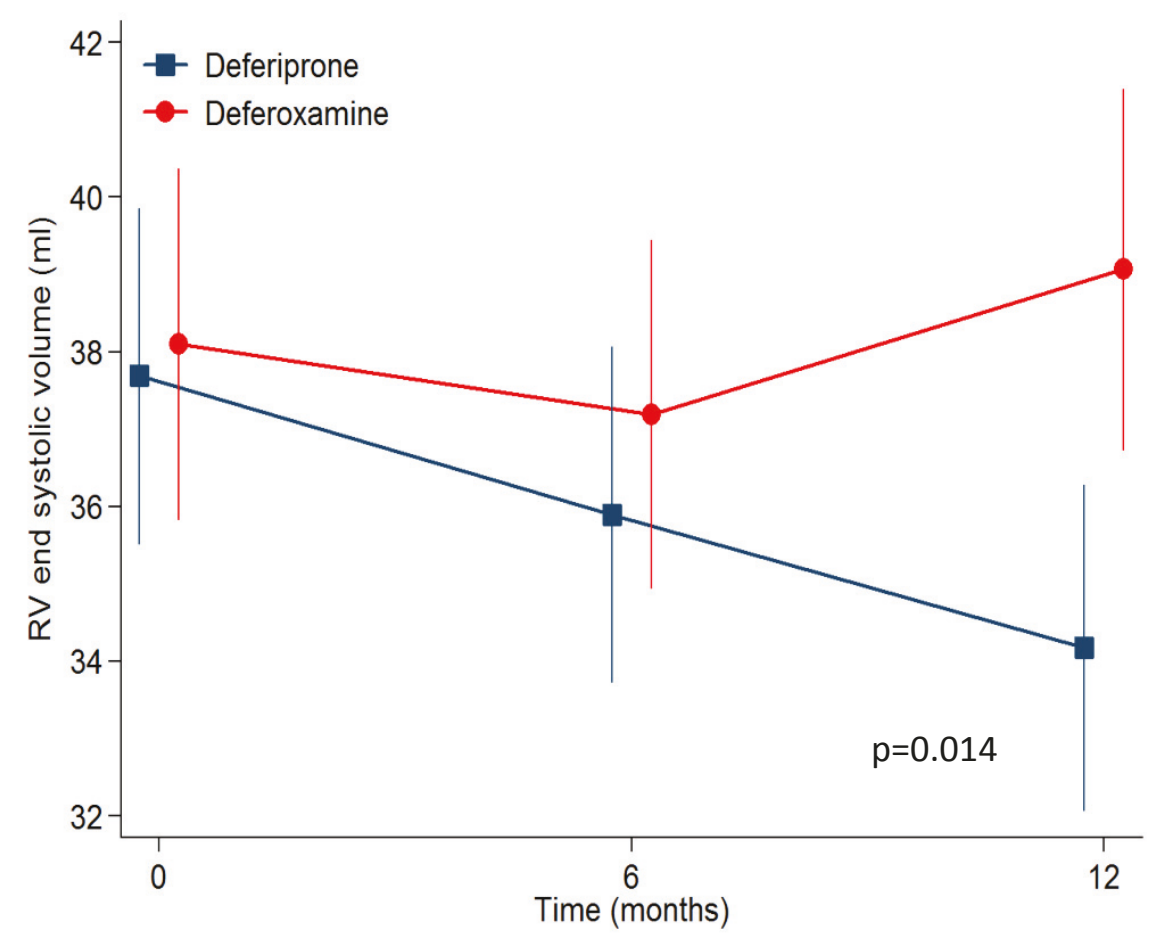

Figure 1 The response in the 2 treatment arms for RVESV showed a significant improvement for patients treated with deferiprone, which was not seen with deferoxamine (12 month difference between drugs $p=0.014$ ).

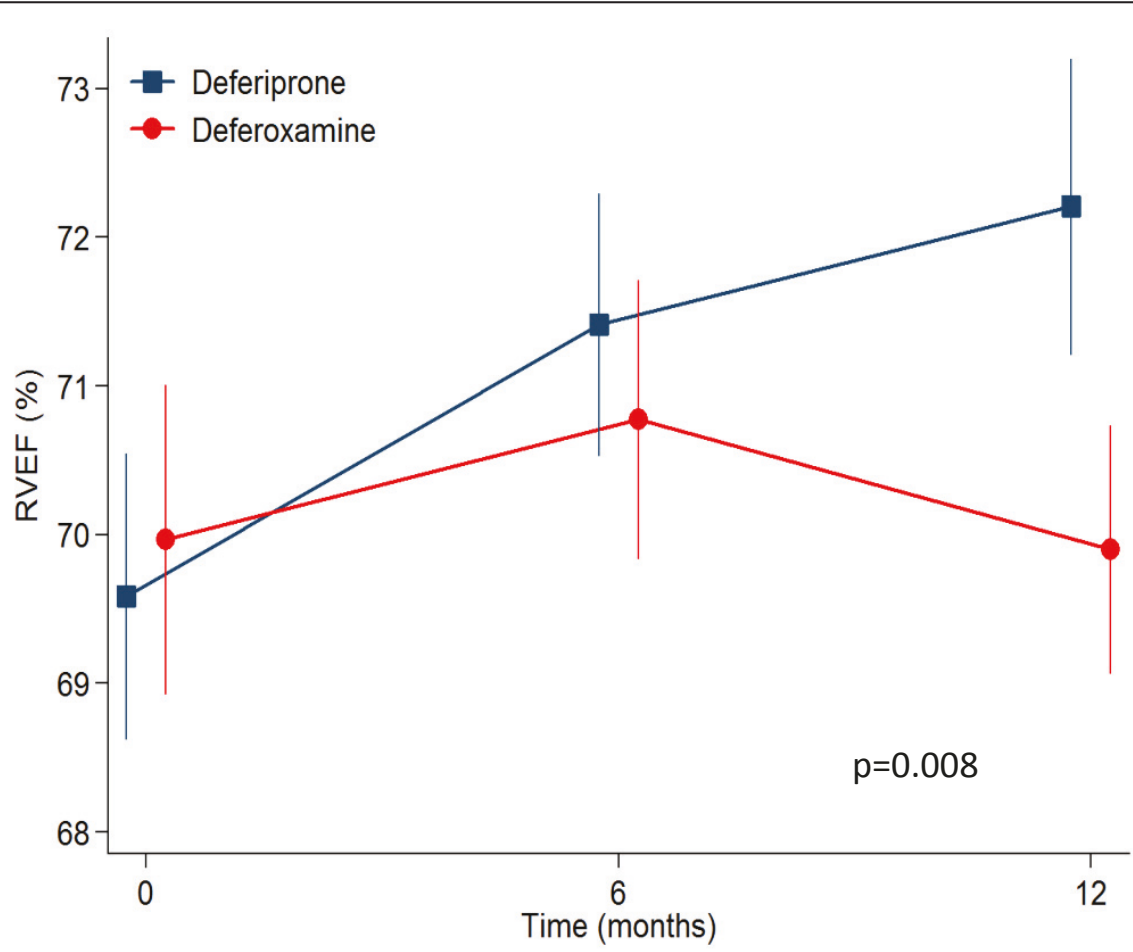

Figure 2 The response in the 2 treatment arms for RVEF showed a significant improvement for patients treated with deferiprone, which was not seen with deferoxamine (12 month difference between drugs $p=0.008$ ) 
for myocardial iron overload, and may have independent prognostic importance, as they do in other cardiac conditions with impaired cardiac function.

\author{
Acknowledgements and Funding \\ This work was supported by the National Institutes for Health Research \\ Cardiovascular Biomedical Research Unit of Royal Brompton Hospital and \\ Imperial College. The original randomized controlled trial (LA16) was \\ sponsored by ApoPharma, but no company funding was received for this \\ study in which the imaging data was reanalyzed.
}

\section{Author details}

'CMR Unit, Royal Brompton \& Harefield NHS Foundation Trust, Sydney Street, London SW3 6NP, UK. ${ }^{2}$ National Heart \& Lung Institute, Imperial College London, Guy Scadding Building, Dovehouse Street, London SW3 $6 \mathrm{LY}$, UK. ${ }^{3}$ Division of Haematology/Oncology, Children's Hospital, 4650 Sunset Boulevard, Los Angeles, CA 90027, USA. ${ }^{4}$ Thalassaemia Unit, Aghia Sophia Children's Hospital, Thivon \& Papadiamantopoulou, Goudi, Athens 115 27, Greece. ${ }^{5}$ Division of Paediatrics and thalassaemia centre, Department of Clinical and Biological Sciences, University of Torino, S. Luigi Gonzaga Hospital, Regione Gonzole 10, Orbassano 10043, Torino, Italy. ${ }^{6}$ First Department of Internal Medicine, University of Athens Medical School, Laiko Hospital, 17 Agiou Thoma Street, Athens 115 27, Greece. ${ }^{7}$ Department of Magnetic Resonance, Institute Euromedica-Encephalos, 3 Rizariou Street, Halandri, Athens 152 33, Greece. ${ }^{8}$ Department of Cardiology, St Richard's Hospital, Western Sussex Hospitals NHS Trust, Chichester, West Sussex, PO19 6SE UK. ${ }^{9}$ Department of Cardiology, The London Chest Hospital, Bonner Road, London E2 9JX, UK. ${ }^{10}$ Department of Biomedical Science and Biotechnology, University of Cagliari, Ospedale Regionale per le Microcitemie. Via Edward Jenner, 09121 Cagliari, Italy. ${ }^{11}$ UCL Cancer Trials Centre, University College London, 90 Tottenham Court Road, London W1T 4TJ, UK.

\section{Authors' contributions}

GCS and FA participated in study design, data analysis and interpretation and manuscript drafting. JPC and MHA performed additional data analysis. $V B, M K, V L, A P, A A, E D G, M A T$ and MAW Served as investigators on the original trial. MR performed statistical analysis. DJP conceived of the study and was responsible for the final manuscript draft. All authors read and approved the final manuscript.

\section{Competing interests}

GCS is a consultant to Novartis and has received honoraria from ApoPharma. FA has received honoraria from Novartis. JPC has received speaker's honoraria from Novartis, Swedish Orphan and ApoPharma. VB is a consultant for ApoPharma. VL has received grant support, consulting fees and lecture fees from ApoPharma and Novartis. AP has received honoraria and research funding from Novartis. RG has served on speakers' bureaus and received research grants from Novartis and ApoPharma. DJP is a consultant to and has served on advisory boards and speakers' bureaus for Novartis, ApoPharma, and Siemens; has received research funding from Novartis; and is a director and stockholder for Cardiovascular Imaging Solutions.

Received: 10 February 2011 Accepted: 6 July 2011

Published: 6 July 2011

\section{References}

1. Olivieri NF, Nathan DG, MacMillan JH, Wayne AS, Liu PP, McGee A, Martin M, Koren G, Cohen AR: Survival in medically treated patients with homozygous beta thalassaemia. N Engl J Med 1994, 331:574-8.

2. Modell $B$, Khan M, Darlison M: Survival in beta thalassaemia major in the UK: Data from the UK Thalassaemia Register. Lancet 2000, 355:2051-2.

3. Rachmilewitz EA, Weizer-Stern O, Adamsky K, Amariglio N, Rechavi G, Breda L, Rivella S, Cabantchik Zl: Role of iron in inducing oxidative stress in thalassemia: Can it be prevented by inhibition of absorption and by antioxidants? Ann N Y Acad Sci 2005, 1054:118-23.

4. Breuer W, Hershko C, Cabantchik Zl: The importance of non-transferrin bound iron in disorders of iron metabolism. Transfus Sci 2000, 3:185-92.
5. Anderson $\sqcup$, Holden $S$, Davis B, Prescott E, Charrier CC, Bunce NH, Firmin DN, Wonke B, Porter J, Walker JM, Pennell DJ: Cardiovascular T2-star $\left(\mathrm{T} 2^{*}\right)$ magnetic resonance for the early diagnosis of myocardial iron overload. Eur Heart J 2001, 22:2171-9.

6. Wood JC, Otto-Duessel M, Aguilar M, Nick H, Nelson MD, Coates TD, Pollack H, Moats R: Cardiac iron determines cardiac $T 2^{*}, T 2$, and $T 1$ in the gerbil model of iron cardiomyopathy. Circulation 2005, 112:535-43.

7. Cohen AR, Galanello R, Pennell DJ, Cunningham MJ, Vichinsky E: Thalassemia. Hematology Am Soc Hematol Educ Program 2004, 14-34.

8. Kirk P, Roughton M, Porter JB, Walker JM, Tanner MA, Patel J, Wu D, Taylor J, Westwood MA, Anderson $\sqcup$, Pennell DJ: Cardiac T2* magnetic resonance for prediction of cardiac complications in thalassemia major. Circulation 2009, 120:1961-8.

9. Modell B, Khan M, Darlison M, Westwood MA, Ingram D, Pennell DJ: Improved survival of thalassaemia major in the UK and relation to $\mathrm{T}^{*}$ cardiovascular magnetic resonance. J Cardiovasc Magn Reson 2008, 10:42.

10. Porter JB: Practical management of iron overload. Br J Haematol 2001, 115:239-52.

11. Kushner JP, Porter JP, Olivieri NF: Secondary iron overload. Hematology 2001, 47-61.

12. Tanner MA, Galanello R, Dessi C, Westwood MA, Smith GC, Nair SV, Anderson $\mathrm{L}$, Walker JM, Pennell DJ: Myocardial iron loading in patients with thalassemia major on deferoxamine chelation. $J$ Cardiovasc Magn Reson 2006, 8:543-7.

13. Anderson $L$, Holden S, Davis B, Prescott E, Charrier CC, Bunce NH, Firmin DN, Wonke B, Porter J, Walker JM, Pennell DJ: Cardiovascular T2-star (T2*) magnetic resonance for the early diagnosis of myocardial iron overload. Eur Heart J 2001, 22:2171-9.

14. Pennell DJ, Berdoukas V, Karagiorga M, Ladis V, Piga A, Aessopos A Gotsis ED, Tanner MA, Smith GC, Westwood MA, Wonke B, Galanello R: Randomized controlled trial of deferiprone or deferoxamine in betathalassemia major patients with asymptomatic myocardial siderosis. Blood 2006, 107:3738-44.

15. Juillière $Y$, Barbier $G$, Feldmann $L$, Grentzinger $A$, Danchin N, Cherrier F: Additional predictive value of both left and right ventricular ejection fractions on long-term survival in idiopathic dilated cardiomyopathy. Eur Heart J 1997, 18:276-80.

16. de Groote P, Millaire A, Foucher-Hossein C, Nugue O, Marchandise X, Ducloux G, Lablanche JM: Right ventricular ejection fraction is an independent predictor of survival in patients with moderate heart failure. J Am Coll Cardiol 1998, 32:948-54.

17. Larose E, Ganz P, Reynolds HG, Dorbala S, Di Carli MF, Brown KA, Kwong RY: Right ventricular dysfunction assessed by cardiovascular magnetic resonance imaging predicts poor prognosis late after myocardial infarction. J Am Coll Cardiol 2007, 49:855-62.

18. Miszalski-Jamka T, Klimeczek P, Tomala M, Krupiński M, Zawadowski G, Noelting J, Lada M, Sip K, Banyś R, Mazur W, Kereiakes DJ, Zmudka K, Pasowicz M: Extent of RV dysfunction and myocardial infarction assessed by CMR are independent outcome predictors early after STEMI treated with primary angioplasty. JACC Cardiovasc Imaging 2010, 12:1237-46.

19. Carpenter JP, Alpendurada F, Deac M, Maceira A, Garbowski M, Kirk P, Walker JM, Porter JB, Shah F, Banya W, He T, Smith GC, Pennell DJ: Right ventricular volumes and function in thalassemia major patients in the absence of myocardial iron overload. J Cardiovasc Magn Reson 2010, $12: 24$

20. Alpendurada F, Carpenter JP, Deac M, Kirk P, Walker JM, Porter JB, Banya W, He T, Smith GC, Pennell DJ: Relation of myocardial T2* to right ventricular function in thalassaemia major. Eur Heart J 2010, 31:1648-54

21. Lorenz CH, Walker ES, Morgan VL, Klein SS, Graham TP: Normal human right and left ventricular mass, systolic function and gender differences by cine magnetic resonance imaging. J Cardiovasc Magn Reson 1999, 1:7-21.

22. Hudsmith LE, Petersen SE, Francis JM, Robson MD, Neubauer SJ: Normal human left and right ventricular and left atrial dimensions using steady state free precession magnetic resonance imaging. I Cardiovasc Magn Reson 2005, 7:775-82.

23. Grothues F, Smith GC, Moon JC, Bellenger NG, Collins P, Klein HU, Pennell DJ: Comparison of interstudy reproducibility of cardiovascular magnetic resonance with two-dimensional echocardiography in normal subjects and in patients with heart failure or left ventricular hypertrophy. Am J Cardiol 2002, 90:29-34. 
24. Grothues F, Moon JC, Bellenger NG, Smith GS, Klein HU, Pennell DJ: Interstudy reproducibility of right ventricular volumes, function, and mass with cardiovascular magnetic resonance. Am Heart J 2004, 147:218-33.

25. Roos-Hesselink JW, Meijboom FJ, Spitaels SE, van Domburg R, van Rijen EH, Utens EM, McGhie J, Bos E, Bogers AJ, Simoons ML: Decline in ventricular function and clinical condition after Mustard repair for transposition of the great arteries (a prospective study of 22-29 years). Eur Heart J 2004, 25:1264-70.

26. Graham TP Jr, Bernard YD, Mellen BG, Celermajer D, Baumgartner H, Cetta F, Connolly HM, Davidson WR, Dellborg M, Foster E, Gersony WM, Gessner IH, Hurwitz RA, Kaemmerer H, Kugler JD, Murphy DJ, Noonan JA, Morris C, Perloff JK, Sanders SP, Sutherland JL: Long-term outcome in congenitally corrected transposition of the great arteries: a multiinstitutional study. J Am Coll Cardiol 2000, 36:255-61.

27. Gatzoulis MA, Clark AL, Cullen S, Newman CG, Redington AN: Right ventricular diastolic function 15 to 35 years after repair of tetralogy of Fallot. Restrictive physiology predicts superior exercise performance. Circulation 1995, 91:1775-81.

28. Meyer P, Filippatos GS, Ahmed MI, Iskandrian AE, Bittner V, Gilbert J, Perry GJ, White M, Aban IB, Mujib M, Dell'ttalia LJ, Ahmed A: Effects of right ventricular ejection fraction on outcomes in chronic systolic heart failure. Circulation 2010, 121:252-8.

29. Di Salvo TG, Mathier M, Semigran MJ, Dec GW: Preserved right ventricular ejection fraction predicts exercise capacity and survival in advanced heart failure. J Am Coll Cardiol 1995, 25:1143-53.

30. Ghio S, Gavazzi A, Campana C, Inserra C, Klersy C, Sebastiani R, Arbustini E, Recusani F, Tavazzi L: Independent and additive prognostic value of right ventricular systolic function and pulmonary artery pressure in patients with chronic heart failure. J Am Coll Cardiol 2001, 37:183-8.

31. Kakhlon O, Manning H, Breuer W, Melamed-Book N, Lu C, Cortopassi G, Munnich A, Cabantchik Zl: Cell functions impaired by frataxin deficiency are restored by drug-mediated iron relocation. Blood 2008, 112:5219-27.

32. Kontoghiorghes GJ, Efstathiou A, Kleanthous M, Michaelides Y, Kolnagou A: Risk/benefit assessment, advantages over other drugs and targeting methods in the use of deferiprone as a pharmaceutical antioxidant in iron loading and non iron loading conditions. Hemoglobin 2009, 33:386-97.

33. Smith G, Pennell DJ, Porter JB, Cappellini MD, Chan LL, El-Beshlawy A, Aydinok Y, Ibrahim H, Li CK, Viprakasit V, Elalfy M, Kattamis A, Habr D, Domokos G, Hmissi A, Taher A: Improvement in right ventricular function following 1 year of deferasirox therapy in patients with $\beta$-thalassemia. Blood 2009, 114:abstract 5106.

34. Pennell DJ, Porter JB, Cappellini MD, El-Beshlawy A, Chan LL, Aydinok Y, Elalfy MS, Sutcharitchan P, Li CK, Ibrahim H, Viprakasit V, Kattamis A, Smith G, Habr D, Domokos G, Roubert B, Taher A: Efficacy of deferasirox in reducing and preventing cardiac iron overload in beta-thalassemia. Blood 2010, 115:2364-71.

35. Pennell DJ, Porter JB, Cappellini MD, Chan LL, El-Beshlawy A, Aydinok Y, Ibrahim H, Li CK, Viprakasit V, Elalfy MS, Kattamis A, Smith G, Habr D, Domokos $G$, Roubert B, Taher A: Continued improvement in myocardial T2* over 2 years of deferasirox therapy in beta-thalassemia major patients with cardiac iron overload. Haematologica 2011, 96:48-54.

36. Pennell DJ, Porter JB, Cappellini MD, Chan LL, El-Beshlawy A, Aydinok Y, Ibrahim H, Li CK, Viprakasit V, Elalfy MS, Kattamis A, Smith G, Habr D, Domokos $G$, Roubert B, Taher A: Continued improvement and normalization of myocardial $\mathrm{T}^{*}$ in patients with $\beta$ thalassemia major treated with Deferasirox (Exjade ${ }^{\oplus}$ ) for up to 3 years. Blood 2010, 116: abstract 4276 .

37. Aessopos A, Farmakis D, Hatziliami A, Fragodimitri C, Karabatsos F, Joussef J, Mitilineou E, Diamanti-Kandaraki E, Meletis J, Karagiorga M: Cardiac status in well treated patients with thalassemia major. Eur J Haematol 2004, 73:359-66.

doi:10.1186/1532-429X-13-34

Cite this article as: Smith et al: Effect of deferiprone or deferoxamine on right ventricular function in thalassemia major patients with myocardial iron overload. Journal of Cardiovascular Magnetic Resonance 2011 13:34.

\section{Submit your next manuscript to BioMed Central and take full advantage of:}

- Convenient online submission

- Thorough peer review

- No space constraints or color figure charges

- Immediate publication on acceptance

- Inclusion in PubMed, CAS, Scopus and Google Scholar

- Research which is freely available for redistribution

Submit your manuscript at www.biomedcentral.com/submit
C Biomed Central 